\title{
Psychosocial risks, burnout and intention to quit following the introduction of new software at work
}

\author{
Mouna Knani*, Pierre-Sébastien Fournier and Caroline Biron \\ Faculty of Business Administration, Université Laval, QC, Canada
}

Received 7 January 2017

Accepted 10 July 2017

\begin{abstract}
.
BACKGROUND: Despite a rich literature on association between psychosocial factors, the demand-control-support (DCS) model and burnout, there are few integrated frameworks encompassing the DCS model, burnout and intention to quit, particularly in a technological context.

OBJECTIVE: This manuscript examines the relationships between psychosocial risks, the demand-control-support (DCS) model, burnout syndrome and intention to quit following the introduction of new software at work.

METHODS: Data was collected from agents and advisors working at a Canadian university and using new study management software. An online questionnaire was sent via the university's internal mail. Finally, 112 people completed the online survey for a response rate of $60.9 \%$.

RESULTS: The results of structural equation modeling show that psychological demands, decision latitude and social support are associated with burnout. It is also clear that burnout, in particular depersonalization and emotional exhaustion, is positively associated with intention to quit.

CONCLUSIONS: The few studies that raise the negative consequences of technology on quality of life in the workplace, and particularly on health, have not succeeded in establishing a direct link between a deterioration of health and the use of technology. This is due to the fact that there are few epidemiological studies on the direct consequences of the use of ITC on health.
\end{abstract}

Keywords: Demand-control-support (DCS) model, burnout, intention to quit, software

\section{Introduction}

Despite a rich literature on associations between psychosocial factors, the demand-control-support (DCS) model and burnout [1,2], there are few integrated frameworks encompassing the DCS model, burnout and intention to quit, particularly in a technological context. Indeed, the repercussions of technology on the work environment remain little explored, which may explain why they are often

${ }^{*}$ Address for correspondence: Mouna Knani, Faculty of Business Administration, Université Laval, QC G1V 0A6, Canada. Tel.: +1 418 2658833; E-mail: mouna.knani.1@ulaval.ca. viewed as soft technologies and vectors of well-being at work [3].

The purpose of this study is to use an integrated framework to examine the relationships between psychosocial risks, the DCS model, burnout and intention to quit following the introduction of new software at work. This paper aims to theoretically examine how technology affects the psychosocial work environment, particularly regarding psychological demands, decision latitude and social support at work. The specific context of this study may shed new light on the connections between psychosocial factors, burnout syndrome and intention to quit. 
A substantive body of research has focused on incentives that lead employees to withdraw from their organization [4, 5]. Many factors have been identified as causes of intention to quit, in particular: job satisfaction [6]; stress [7]; organizational change [8]; downsizing [9]; and burnout [10, 11, 12].

Studies exploring the relationship between burnout and intention to quit have taken place primarily in the health care sector [12-14]. Indeed, burnout syndrome has often been limited to a few categories of professions, especially helping professionals (teachers, nurses, physicians) [11]. On the other hand, employees operating in technology-driven environments are also exposed to burnout [15].

Technology is considered to enhance employees' decision-making abilities, informational competence and communication skills [3]. It is also known to save time, to facilitate the execution of tasks and to considerably reduce the physical demands of work [15]. In sum, it plays a strategic role in the organization. However, studies also show that computerization and automation are important factors affecting psychosocial atmosphere in the workplace $[3,15,16]$ and intention to quit [17]. Other studies have shown that the inability to control the flow of information and technology and continuous changes in work methods lead to stress induced by the use of technology and even to burnout [17].

\section{Burnout syndrome and its dimensions}

Burnout starts with chronic feelings of stress resulting from an imbalance between organizational demands and physical and mental capabilities [18]. Burnout is characterized by the appearance of three progressively symptomatological traits: emotional exhaustion, depersonalization (or cynicism), and reduced personal accomplishment [19]. Although burnout syndrome is not yet recognized as an occupational disease [20], a majority of researchers link it to work organization and situate it specifically within a stressful professional environment [18, 21-24]. Emotional exhaustion is the central emotional component of burnout that triggers the burnout process [19]. This component points to a depletion of emotional resources caused by sustained occupational stress. Depersonalization (cynicism) is the interpersonal dimension of burnout and points to detachment in interpersonal relations [19]. Personal accomplishment represents the self-assessment dimension of burnout is manifested by lowered self-esteem and self-depreciation [20]. The continuous imbalance between work demands and capabilities leads to emotional exhaustion $[18,25]$, accompanied by attitudinal and behavioural changes, namely depersonalization and reduced personal accomplishment [26].

Since, the interactions between emotional exhaustion, depersonalization and personal accomplishment have been studied extensively and validated in the literature $[27,20]$. Our study will not verifies theses hypotheses. We will direct attention to other research hypotheses likely to make new contributions to the existing literature.

\section{Relationships between the DCS model and burnout in a technological context}

\subsection{Relationship between psychological demand and emotional exhaustion}

Studies confirm the relationship between high levels of psychological demand and burnout [28-30] and particularly emotional exhaustion [31, 32]. High levels of psychological demand significantly increase emotional exhaustion [31, 33]. The longitudinal study of Van der Ploeg [34] also reports positive relationships between psychological demands, depersonalization and emotional exhaustion.

When it comes to technology change, these relationships are almost unexplored in the literature. However, the advent of new technology has been associated with high levels of psychological demand [17]. According to these researchers, technology has impacts on the pace and volume of work. The ongoing development of, and search for, new technologies involves technical and technological change, and their assimilation in order to improve the quality of services [35]. However, lack of training and the complexity and inadequacy of technology systems can induce additional workload and stress for workers [35].

Hypothesis 1. In a technological context, a positive relationship exists between psychological demand and emotional exhaustion

\subsection{Relationships between decision latitude, personal accomplishment and emotional exhaustion}

Studies have shown that low decision latitude is associated with high levels of burnout [36, 37]. 
Alexander [38] and Kowalski [39] show that decision latitude is negatively associated with emotional exhaustion and depersonalization, and positively linked to personal accomplishment. But Esciriba Aguir [31] fail to find a significant relationship between the use of skills (a dimension of decision latitude) and the appearance of burnout, notably emotional exhaustion. This may be explained by the fact that decision latitude is a regulating variable of perceived job strain [31,36]. A recent study [23] reported that the effect of workload on perceived job risk is moderated by latitude decision (measured by control over work scheduling and overtime). This effect is reported to be weaker under conditions of high control [23]. These relationships have not been tested following a technological change. In addition, studies reveal that employees who use technology as an important aspect of their work follow a process that forces them to comply with operating procedures and requirements that decrease their decision latitude [40]. Greenan [41] hypothesize that employees who work for a technology-driven company are more likely to have low decision latitude. Workers are often called upon to strictly follow instructions in the use of the technology. This leads to a form of hyperrationalization, standardizing not only organizational goals, but also prescribing employees' operating procedures [42]. In connection with this standardization, Chevallet [3] state that the employee is faced with working according to a computerized process that leaves no opportunity for mobilizing his skills and knowledge. Furthermore, softwares contribute to enhance performance during complex procedures. However, it also affects services by depersonalizing it, which has a negative impact on the employee's psychological state and job performance [3]. Indeed, employees who face less decision latitude in the accomplishment of their tasks and the possibility of participating in decision making also experience fewer feelings of personal accomplishment [3]. Other studies have shown that some employees develop a job-related defensive ideology as a protective mechanism against sustained job strain. It is exhibited as depersonalization at work in order to cope with the lack of decision latitude [43]. This leads us to hypothesize that:

Hypothesis 2. In a technological context, a positive relationship exists between decision latitude and loss of personal accomplishment

Hypothesis 3. In a technological context, a negative relationship exists between decision latitude and depersonalization

\subsection{Relationships between social support, emotional exhaustion and personal accomplishment}

Poor social support in the workplace is associated with a high level of emotional exhaustion and depersonalization [44, 45], and a low level of personal accomplishment [18]. Wilk [46] show that supervisor support has a greater impact on emotional exhaustion than psychological demand. Studies confirm that poor social support from superiors is linked to a high level of emotional exhaustion [31]. Also, lack of social support from the supervisor is positively associated with emotional exhaustion and depersonalization, and negatively linked to personal accomplishment [34]. Shaufeli [47] confirm that social support deprived of reciprocity leads to a depletion of emotional resources and, consequently, to emotional exhaustion. In their longitudinal study, Van der Ploeg [34] show that poor social support from supervisors and work colleagues increases emotional exhaustion, leading to depersonalization and the loss of personal accomplishment. On the other hand, other studies report the absence of a significant relationship between social support in the workplace, and the emergence of burnout [48].

These associations have not been studied in a technological context. Furthermore, studies have shown that technology may be an expansion factor of work collectives, but also an isolation factor that affects social support in the workplace, namely, direct exchange, sociability among colleagues, mutual aid relations, and cooperation [49]. Employees may be very close physically, yet at the same time, very distant socially. Capgemini Consulting (2010) suggest that technology may cannibalize human relations in the workplace, depersonalize relations between employees and further impoverish social ties between employees. In fact, mobile technologies and even office technology often replace direct exchange between employees and foster erosion within the group [3]. This leads us to hypothesize that poor social support in the workplace in a technologydriven environment affects employees' health and gives rise to burnout.

Hypothesis 4. In a technological context, a negative relationship exists between social support and emotional exhaustion

Hypothesis 5. In a technological context, a positive relationship exists between social support and personal accomplishment 


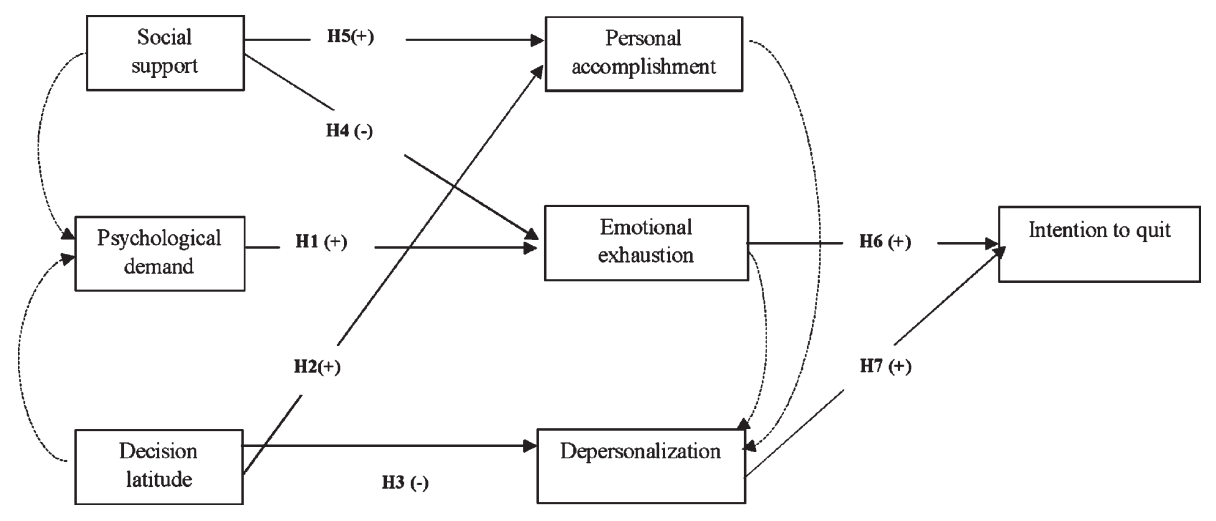

Fig. 1. Relations between DCS, burnout and intention to quit.

\section{Association between burnout and intention to quit}

Meyer [50] define organizational involvement as a psychological state that reflects the relationship between employees and their organization. An employee who disengages from his or her company manages to set aside feelings and relationships with his colleagues and organization [11]. Fournier [51] highlight that burnout has an impact on disengagement through a strong rejection of the organization's values. In other cases, the employee tends to view the organization and entourage in a detached and objective manner (depersonalization). This is a psychological escape mechanism, a means of adaptation to cope with discontent towards the organization or work colleagues $[10,52]$. Thus, intention to quit is a decision that may be linked to emotional exhaustion [28], or to depersonalization, in which the employee no longer expresses a moral duty (cynicism) towards his or her work organization. In a technological context, this problem remains an almost unexplored field of study. This leads us to hypothesize that:

Hypothesise 6. In a technological context, a positive relationship exists between emotional exhaustion and intention to quit

Hypothesis 7. In a technological context, a positive relationship exists between depersonalization and intention to quit. The conceptual model and hypotheses are presented in Fig. 1.

\section{Methodology}

\subsection{Data collection and sample characteristics}

This study was conducted in a large Canadian university facing problems related to increased absen- teeism rates and an apparent increase in burnouts among agents and advisors following the implementation of new study management software to replace an older program. We used a mixed approach, namely a qualitative data collection followed by a survey questionnaire. Qualitative methods (focus group, analyses of the real work activity and exploration of potential solutions at the end of the process) were used in the first stages of research primarily to explore the daily problems associated with this population [Fournier et al., 2013].

This article is based on the data collected during the quantitative phase. This phase was chosen because the goal of the study is to quantify the impact of psychosocial factors on the appearance of burnout and intention to quit. The targeted population initially consisted of 195 agents and advisors involved in study management who used the new study management software. The list of employees was developed using the university employees' telephone directory. At the time of data collection, 11 employees were on long-term leaves of absence (disability or maternity) were eliminated from this list. Data collection took place online and anonymously. A postcard inviting employees to complete the online questionnaire was sent via the university's internal mail system. Two reminder emails were sent to respondents, inviting them to complete the survey. Finally, 112 people completed the online survey for a response rate of $60.9 \%$. This sample size is less than the minimal sample size needed for a survey conducted on a random sample, which is $130 .^{1}$

The Research Ethics Committee on human beings of our university approved the study and provided us

\footnotetext{
${ }^{1} \mathrm{SS}=(\mathrm{Z} \text {-score })^{2} * \mathrm{p} *(1-\mathrm{p}) /(\operatorname{margin} \text { of error })^{2} . \mathrm{SS}=(1.96)^{2} *$ $0.5^{*}(1-0.5) /(0.05)^{2} . \mathrm{SS}=384 \mathrm{SS}$ adjusted $=(\mathrm{SS}) / 1+[(\mathrm{SS}-1) /$ population $]=(384) / 1+[(384-1) / 196]=130(Z$-score is 1.96 for a $95 \%$ confidence level).
} 
with a certificate of compliance. All the agents and advisors that agreed to complete the questionnaire signed an informed Consent Form.

The final sample was made up of 50\% of respondents aged between 46 and 55. Some $43 \%$ of the respondents lived with a spouse and had dependent children, while $12.5 \%$ lived alone and with no dependent child. The sample contained 104 women $(92.9 \%$ of respondents). The majority of the respondents $(72.4 \%)$ had a university or college-level degree. Also, $(86.7 \%)$ of the respondents were permanent employees. Almost all the respondents (94.6\%) spent most of their time at work on study management and were big users of the new software.

\subsection{Measurement of constructs}

The three dimensions of burnout were measured using the Maslach Burnout Inventory (MBI) of Maslach \& Jackson [1981, 1986]. This inventory is widely used in the literature and its reliability and validity have been confirmed in several countries and in various sectors of employment [53, 54]. For example, Poghosyan [54] examined the instrument in eight countries (United States, Canada, United Kingdom, Germany, New Zealand, Japan, Russia and Armenia) and reported reliability coefficients exceeding (0.70). The MBI consists of 22 statements: emotional exhaustion (9 statements), depersonalization (5 statements) and personal accomplishment (8 statements). Seven possible answers to each statement were retained: never (0), a few times per year (1), once a month (2), a few times per month (3), once a week (4), a few times per week (5), every day or always (6). For emotional exhaustion, the scoring results total of the nine statements determines its level. A total of 17 or less is equivalent to low-level burnout. A total between 18 and 29 inclusive refers to moderate burnout. A total over 30 refers to high-level burnout. For depersonalization, the scoring results total of the five statements is used to identify three levels of depersonalization: low (total of 5 or less), moderate (total between 6 and 11) and high (total of 12 and more). Finally, for personal accomplishment the level is low when the score is 40 or more, moderate when the total is between 34 and 39 and high when the total is 33 or less.

Psychological demand, decision latitude and social support constructs were measured by 9.9 and 8 statements respectively, all taken from Karasek [55]. The reliability of these instruments was confirmed by
Table 1

Reliability of the measures

\begin{tabular}{lcc}
\hline Construct & Number of items & Cronbach's Alpha \\
\hline Decision latitude & 9 & 0.701 \\
Social support & 8 & 0.913 \\
Psychological demand & 9 & 0.803 \\
Emotional exhaustion & 5 & 0.901 \\
Depersonalization & 5 & 0.730 \\
Personal accomplishment & 8 & 0.688 \\
Intention to quit & 5 & 0.825 \\
\hline
\end{tabular}

Karasek [55] in a study carried out in four countries, namely the United States, Canada, The Netherlands and Japan. All the statements were measured using a scale of four possible answers: strongly disagree (1), disagree (2), agree (3) and strongly agree (4). Finally, intention to quit was measured by five statements inspired by [56] and adapted to the study context. For example, "I have definitely contemplated leaving the university since the introduction of software name". The scale consists of five possible answers ranging from strongly disagree (1) to fully agree [5].

\section{Results}

\subsection{Reliability of the measuring instruments}

Table 1 indicates Cronbach's Alpha values for each measure. All the scores exceeded the threshold of 0.70 , except the "personal accomplishment" construct with a score very close $(0.688)$ to the threshold limit nonetheless. Therefore, the reliability of the measuring instruments was deemed acceptable. The results confirm scores reported in previous studies and support the psychometric quality of the measuring instruments selected.

\subsection{Model fit}

The conceptual framework and the research hypotheses were tested using a structural equations model and EQS (6.1) software. The maximumlikelihood method was applied to estimate the model and corrected statistics used to address non-normal data.

The evaluation of model fit was carried out on the basis of several indicators: the Chi-square $(\chi 2)$, Chisquare divided by the number of degrees of freedom $(\chi 2 / \mathrm{ddl})$, Non-Normed Fit Index (NFI), Comparative Fit Index CFI, [57], Incremental Fit Index (IFI), McDonald Fit Index (MFI), RMSEA and the Root 


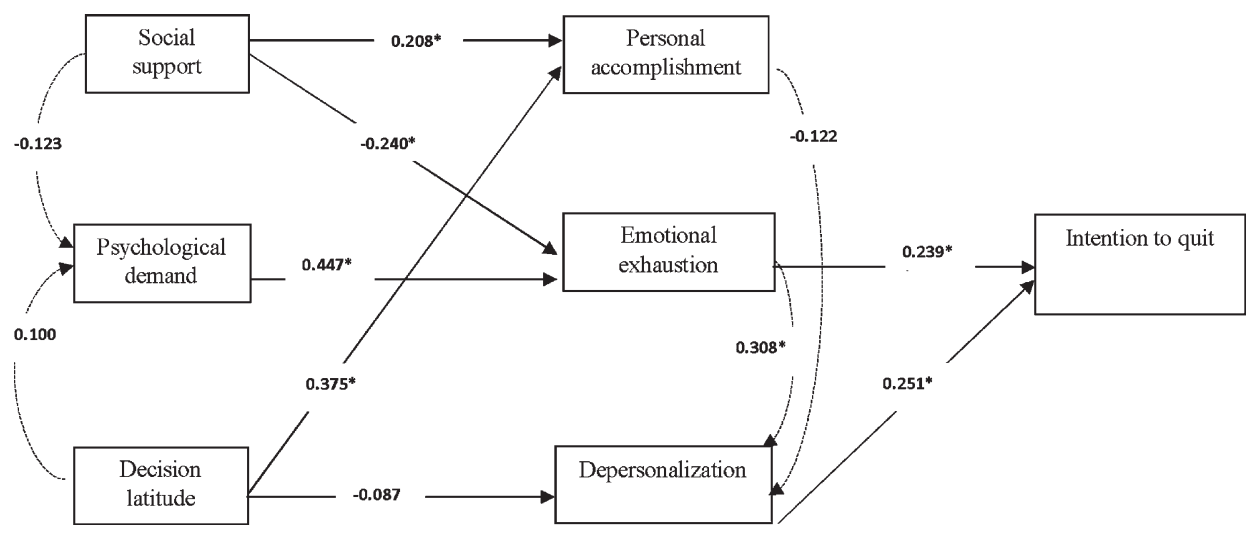

Fig. 2. Results of the research hypotheses test.

Mean-Square Residual (RMSR). The value of the $\mathrm{S}-\mathrm{B} \chi 2$ index was not significant since the value $\mathrm{p}$ $(p=0.073)$ was greater in terms of the risk of error established at 0.05 at the onset of this study. The value of $\mathrm{S}-\mathrm{B} \chi 2$ divided by the number of degrees of freedom was less than $3(\mathrm{~S}-\mathrm{B} \times 2 / \mathrm{ddl}=1.707)$. The index values of IFI (0.910) and MFI (0.953) exceeded 0.90. Only the index value of CFI was at the limit of acceptability (0.895). Finally, the values of RMR (0.045) and RMSEA (0.099) were below 0.10. Overall, these results confirmed the goodness of fit of the model with the data observed.

\subsection{Verification of research hypotheses}

The results of the research hypotheses test are presented in Fig. 2. Hypothesis (1) is confirmed because a positive $(\beta=0.447)$ and significant $(t=4.445)$ association exists between psychological demand and emotional exhaustion. The effect of decision latitude on personal accomplishment is positive $(\beta=0.375)$ and significant $(t=3.522)$ which confirms Hypothesis (2). Hypothesis (3) is not supported because the effect of decision latitude on depersonalization is not significant $(\beta=-0.087 ; t=-0.732)$. The impact of social support on emotional exhaustion is negative and significant $(\beta=-0.240 ; t=-2.390)$, which confirms Hypothesis (4). The results also show a positive $(\beta=0.208)$ and significant $(t=1.952)^{2}$ effect of social support on personal accomplishment which confirms Hypothesis (5). The effect of emotional exhaustion on intention to quit is positive $(\beta=0.239)$ and significant $(t=2.098)$, thereby confirming Hypothesis (6).

\footnotetext{
2 The value of 1.952 is very close to the critical value of 1.96 of the Student's $t$-test. Therefore, the relation is considered significant.
}

Finally, Hypothesis (7) is confirmed by a positive and significant effect of depersonalization on intention to quit $(\beta=0.251 ; t=-2.209)$.

\section{Discussion}

The purpose of this study was to expand knowledge on the impact of psychosocial risks on the emergence of burnout and intention to quit. This study differs from previous studies owing to its integrated conceptual framework and to the particular context of its field of study, the introduction of new technology.

The results of this study confirm that psychological demand is positively associated with emotional exhaustion. The study supports the results of previous researches with respect to the impact of increased psychological demand on burnout and emotional exhaustion, in particular [44]. In the context of the introduction of a new technology (new study management software), employees (agents and advisors) are subject to new requirements and must cope with all the inconveniences associated with learning new functions and various applications, data transfer and work modeling. Obviously, this learning process must take place while continuing to respond to the immediate requests of service users (students and other employees in other university sectors) and ensuring a high standard of quality service. The situation would appear to be sufficient for psychological strain, and emotional exhaustion in particular, to surface.

This study highlights the role of social support at work and, above all, the negative effect of social support at work on emotional exhaustion. Thus, support from superiors and work colleagues contributes 
to reducing emotional exhaustion caused by strong psychological demand. Previous research has shown that instrumental support (material) and emotional support mitigate the negative consequences of a pathogenic work environment [58]. Indeed, these two types of support counterbalance the negative consequences of psychological stress dependant, in turn, on social and psychological integration and the confidence shown by colleagues and supervisors [58]. Indeed, a poor relationship between subordinates and supervisors or between work colleagues, friction, and continuous misunderstandings can generate feelings of stress and emotional exhaustion.

The results show that support in the workplace does not significantly decrease psychological demand, therefore does not dampen perceptions of a heavy workload. In the context of this study, the stress caused by difficulties associated with using the new study management software and some employees' aversion to technology increase psychological demand in the workplace. The effect of psychological demand on emotional exhaustion is counterbalanced in part by the support that agents and advisors receive from colleagues and supervisors. Social support in the workplace helps alleviate the effect of psychological demand on emotional exhaustion without eliminating it completely. Indeed, the results show that the weight of the impact of psychological demand on emotional exhaustion is almost twice as great as that of social support at work on emotional exhaustion ( 0.447 vs. 0.240).

Social support at work also influences personal accomplishment. The results obtained support those reported by Sargent [58], in that employees working under conditions of high organizational support report greater satisfaction in the workplace and less loss of personal accomplishment. This study shows that social relations at work have an impact on stress in the workplace, independent of psychological demand and decision latitude. The study supports a direct and negative impact of social support on emotional exhaustion and draws attention to personal accomplishment. Consequently, social support at work is a regulating factor of burnout, since it reduces emotional exhaustion and emphasizes personal accomplishment. Our results confirm the relationships found in the literature [59, 60]. Although not a cure-all for all psychological health problems, social support at work remains a key mitigating factor of stress and burnout. Social support plays an important role in the introduction of new technology.
This study also shows that burnout, namely emotional exhaustion and depersonalization, lead a person to quit, which confirms results observed in previous studies [10]. Emotional exhaustion and depersonalization are reflections of psychological stress experienced in the workplace, amplified by the effect of an accumulation of working circumstances. Burnout renders an employee vulnerable and instills in him a desire to leave his job.

The adoption of new technology and innovation in an organization system (services and production processes) increases its performance and efficiency. However, the introduction stage of a new technology is accompanied with an increase in perceived workload among employees. The workload demand change may have a detrimental impact on the different dimensions of burnout and influence employees' health [22]. Future research is encouraged to integrate the impact of new technology adoption on employee's mental health (e.g., anxiety and depression) and physical health (e.g., cardiovascular disease).

After the introduction of the new software system, the disadvantages of technology combined with organizational factors affecting employees and the work organization, should be identified and addressed. This assessment framework is necessary in the event of a deterioration of working conditions and the emergence of psychological stress that impedes the work process, as is truly the case of our research sample made up of study management agents and advisors.

\section{Limitations}

This study highlights the impact of the psychosocial environment on burnout. However, the literature reports that burnout is also influenced by employees' individual characteristics. It would be interesting if future studies were to integrate these variables to examine their direct or even moderating effects.

In this research, the size of the population under study and the number of observations obtained did not allow us to consider integrating and evaluating individual characteristics with regard to various relationships between the working environment and burnout. The use of larger databases might allow an assessment of the nature of the effect on these individual characteristics using Analysis of variance and multi-group structural equation modeling. Future researches is encouraged to test the effect of individual characteristics (e.g., age, family situation, 
years of work experience, personality, and technology acceptance/aversion) and occupational characteristics. For instance, previous research reported a significant effect of occupational characteristics [22], psychological characteristics (e.g., personality [23]), and demographic characteristics $[21,61]$ on burnout dimensions (emotional exhaustion, depersonalization, and professional efficacy).

This study focuses on the adoption of a specific technology. Future studies would generalize the model to other types of new technologies and different degrees of innovation. This research provides a starting point for future research examining the consequences of new technology implementation on employee's health.

This research used data collected after the implementation of new technology. It would be interesting if future research were to test the conceptual framework on the basis of data collected in three phases: before, during, and after the introduction of new technology. A longitudinal study might then examine the evolution in the levels of the three dimensions of burnout and their impact on intention to quit.

\section{Implications for practice}

Burnout is a complex phenomenon, characterized by emotional exhaustion, reduced personal accomplishment (or ineffectiveness), and depersonalization (or cynicism) Burnout is caused by many workplace factors such as increase in psychological demand, decrease in latitude decision (or control) and social support.

Burnout has a detrimental effect on the organization's productivity. The academic literature support burnout effects on mental health, physical health, job performance, and absenteeism. Burnout has also a negative impact on employee's intention of leaving, leading to increase in turnover and costs of filling positions and training new employees. Practitioners should be aware of the reality of this syndrome and develop preventive measures to reduce the level of burnout and its negative consequences on employee health and commitment, by early identification of occupational factors that may cause its emergence among employees.

This research emphasize $s$ the impact of the implementation of new technology on the perception of psychological demand. Despite the positive effect of new technology on organization perfor- mance (e.g., enhancing productivity, offer value, and service quality), the first stage of implementation increase occupational stressors, requiring significant efforts by employees to familiarize themselves with the new technology and use it in day-today operations. Employees should be provided the necessary training and the required resources to realize the tasks and meet the organizations expectations.

This research underscores the importance of social support, from both supervisors and peers, in decreasing burnout. Social support attenuates the effects of higher psychological demand on burnout. Managers should encourage the development of brief frequent teamwork meetings and exchanges among employees, and between employees and their immediate supervisors.

Indeed, frontline managers and supervisors should be trained to be aware of the symptoms and indicators of burnout (e.g., anxiety, frustration, attitude change, increased absenteeism, and job satisfaction and productivity) and of how to prevent this syndrome among employees. Organizations who intend to adopt new technologies (e.g., new devices, applications, and software) should develop program training for both the use of this new technology and the prevention of its negative impact on occupation stressors.

\section{Conclusion}

In conclusion, the few studies that raise the negative consequences of technology on quality of life in the workplace, and particularly on health, have not succeeded in establishing a direct link between a deterioration of health and the use of technology. This is due to the fact that there are few epidemiological studies on the direct consequences of the use of ITC on health. This study does not empirically examine the impact of the perception of a new management technology tool on organizational factors, burnout and intention to quit. It would be interesting to integrate the technology variable into future research in order to validate its impact on the psychosocial environment in the workplace and, above all, the intention to quit.

\section{Conflict of interest}

None to report. 


\section{References}

[1] Blom V, Bodin L, Bergström G, Svedberg P. Applying the demand-control-support model on burnout in managers and non-managers. International $\mathrm{J}$ of Workplace Health Management. 2016;9(1):110-122.

[2] Galletta M, Portoghese I, D'Aloja E, Mereu A, Contu $\mathrm{P}$, Coppola RC, Campagna M. Relationship between job burnout, psychosocial factors and health care-associated infections in critical care units. Intensive and Critical Care Nurs. 2016;34:51-8.

[3] Chevallet R, Moatty F. Impact des TIC sur le rythme, l'autonomie et le contrôle. Dans Klein T, Ratier D. (Coordinateurs). L'impact des technologies sur les conditions de travail. 1997;85-105.

[4] Cohen A. Work commitment in relation to withdrawal intentions and union effectiveness. $\mathrm{J}$ of Bus Research. 1993;26:75-90.

[5] Paillé P. Engagement organisationnel, intention de retrait et comportements citoyens : L'influence de la satisfaction au travail. Revue de GRH. 2004;52:31-46.

[6] Lambert SJ. Added benefits: The links between work-life benefits and organizational citizenship behavior. Academy of Management Journal. 2000;43:801-15.

[7] Tuten TL, Neidermeyer PE. Performance, satisfaction and turnover in call centers. The effects of stress and optimism. Journal of Business Research. 2002;56:1-9.

[8] Iverson R, Pullman J. Determinants of voluntary turnover and layoffs in an environment of repeated downsizing following a merger: An event history analysis. J of Management. 2000;26(5):977-1003.

[9] McElroy J, Morrow PC, Rude SN. Turnover and organizational performance: A comparative analysis of the effects of voluntary, involuntary, and reduction-in-force turnover. Journal of Applied Psychology. 2008;86(6):1294-9.

[10] Dall'Ora C, Griffiths P, Ball J, Simon M, Aiken LH. Association of $12 \mathrm{~h}$ shifts and nurses' job satisfaction, burnout and intention to leave: Findings from a cross-sectional study of 12 European countries. BMJ Open. 2015;5(9):8331.

[11] Wong CA, Laschinger HKS. The influence of frontline manager job strain on burnout, commitment and turnover intention: A cross-sectional study. International Journal of Nursing Studies. 2015;52(12):1824-33.

[12] Leineweber C, Chungkham HS, Lindqvist R, Westerlund H, Runesdotter S, Alenius LS, Tishelman C. Nurses' practice environment and satisfaction with schedule flexibility is related to intention to leave due to dissatisfaction: A multi-country, multilevel study. Intern J of Nur Studies. 2016;58:47-58.

[13] Basar U, Basim N. A cross-sectional survey on consequences of nurses' burnout: Moderating role of organizational politics. J of Ad Nur. 2015.

[14] Chênevert D,Jourdain G, Vandenberghe C. The role of highinvolvement work practices and professional self-image in nursing recruits' turnover: A three-year prospective study. Inter J of Nursing Studies. 2016;53:73-84.

[15] Ter Hoeven CL, van Zoonen W, Fonner KL. The practical paradox of technology: The influence of communication technology use on employee burnout and engagement. Communication Monographs. 2016;83(2):239-63.

[16] Porter G, Kakabadse NK. HRM perspectives on addiction to technology and work. $\mathrm{J}$ of Management Deve. 2006;25(6):535-60.
[17] Knani M, Fournier PS. Burnout, job characteristics, and intent to leave: Does work experience have any effect. J of Emerging Trends in Economics and Management Sciences. 2013;4(4):403.

[18] Adriaenssens J, De Gucht V, Maes S. Determinants and prevalence of burnout in emergency nurses: A systematic review of 25 years of research. Inter J of Nurs Studies. 2015;52(2):649-61.

[19] Maslach C. Burnout: A multidimensional perspective; 1993.

[20] Leiter MP, Maslach C. The impact of interpersonal environment on burnout and organizational commitment. J of Orga Behavior. 1988;9(4):297-308.

[21] Oliveira RV, Schneider V, Bonafé FSS, Maroco J, Campos JADB. Occupational characteristics and Burnout Syndrome in Brazilian correctional staff. Work. 2016;55(1): 215-23

[22] Näswall K, Burt CD, Pearce M. The moderating effect of control over work scheduling and overtime on the relationship between workload demands and perceived job risk. Work. 2015;51(3):571-7.

[23] Ahmadpanah M, Torabian S, Dastore K, Jahangard L, Haghighi M. Association of occupational burnout and type of personality in Iranian general practitioners. Work. 2015;51(2):315-9.

[24] Viljoen M, Claassen N. Cynicism as subscale of burnout. Work. 2017;(Preprint):1-5.

[25] Hooper C, Craig J, Janvrin D, Wetsel M, Reimels E. Compassion satisfaction, burnout, and compassion fatigue among emergency nurses compared with nurses in other selected inpatient specialties. J Emerg Nurs. 2010;36:420-7.

[26] Maslach C, Schauffli WB, Leitter MP. Job burnout. Annual Rev of Psy. 2001;52:397-422.

[27] Cordes CL, Dougherty TW, Blum M. Patterns of burnout among managers and professionals: A comparison of models. J of Org Behavior. 1997;78:685-701.

[28] Mark GM, Smith AP. Stress models: A review and suggested new direction. Occupational Health Psychology. 2008;3:111-44.

[29] Nahrgang JD, Morgeson FP, Hofmann DA. Safety at work: A meta-analytic investigation of the link between job demands, job resources, burnout, engagement, and safety outcomes. J of Applied Psychology. 2011;96(1):71.

[30] García-Sierra R, Fernández-Castro J, Martínez-Zaragoza F. Relationship between job demand and burnout in nurses: Does it depend on work engagement? Journ of Nursing Management. 2013;24(6):780-8.

[31] Escribá-Agüir V, Pérez-Hoyos S. Psychological well-being and psychosocial work environment characteristics among emergency medical and nursing staff. Stress and Health. 2007;23(3):153-60.

[32] Sorour AS, El-Maksoud MMA. Relationship between musculoskeletal disorders, job demands, and burnout among emergency nurses. Advanced Emergency Nursing Journal. 2012;34(3):272-82.

[33] García-Izquierdo M, Ríos-Rísquez MI. The relationship between psychosocial job stress and burnout in emergency departments: An exploratory study. Nurs Outlook. 2012;60(5):322-9.

[34] Van Der Ploeg E, Kleber RJ. Acute and chronic job stressors among ambulance personnel: Predictors of health symptoms. Occup and Envir Med. 2003;60(1):40-6.

[35] Carayon P, Karsh BT. Sociotechnical issues in the implementation of Iimaging technology. Behaviour and Information Technology. 2009;19(4):247-62. 
[36] Bakker AB, Demerouti A, Euwema MC. Job resources buffer the impact of job demands on burnout. J of Occup Health Psychology. 2005;10(2):170-80.

[37] Lindblom KM, Linton SJ, Fedeli C, Bryngelsson IL. Burnout in the working population: Relations to psychosocial work factors. Inter $\mathrm{J}$ of Behavioral Med. 2006;13(1):51-9.

[38] Alexander DA, Klein S. Caring for others can seriously damage your health. Hosp Med. 2016;2(264):267.

[39] Kowalski C, Ommen O, Driller E, Ernstmann N, Wirtz MA, Köhler T, Pfaff H. Burnout in nurses-the relationship between social capital in hospitals and emotional exhaustion. J of Clinical Nurs. 2010;19(11-12):1654-63.

[40] KleinT. L'évolution des TIC dans les entreprises. Publié dans le rapport L'impact des technologies sur les conditions de travail, Klein T, Ratier D. (Coor.). 2012;266:19-36.

[41] Greenan N, Hamon-Cholet S, Moatty F, Rosanvallon J. TIC et conditions de travail, Les enseignements de l'enquête COI, rapport de recherche. Centre d'études de l'emploi, Noisy-le-Grand. 2012.

[42] Burlet M. Chevallet R, Pradere T. Hyper-rationalisation organisationnelle et technique: Quand l'analyse de l'activité et de ses effets révèle de nouveaux principes organisationnels. Actes SELF. 2009.

[43] Marchand A, Durand P. Psychological distress, depression, and burnout: Similar contribution of the job demand-control and job demand-control-support models? $\mathrm{J}$ of Occu and Envir Med. 2011;53(2):185-9.

[44] Bourbonnais R, Comeau M, Vézina M, Dion G. Job strain, psychological distress, and burnout in nurses. Amer J of Industrial Medicine. 1998;34(20):28.

[45] Bourbonnais R, Comeau M, Vézina M. Job strain and evolution of mental health among nurses. J of Occupat Health Psychology. 1999;4(2):95-107.

[46] Wilk SL, Moynihan LM. Display rule" regulators": The relationship between supervisors and worker emotional exhaustion. J of Applied Psychology. 2005;90(5):917.

[47] Schaufeli WB, Bram PB. Burnout: An overview of 25 years of research and theorizing. The Handbook of Work and Health Psychology. 2003;2:282-424.

[48] Rafferty Y, Friend R, Landsbergis PA. The association between job skill discretion, decision authority and burnout. Work and Stress. 2001;15:73-85.
[49] Ratier D, Bézard JM. Comment les TIC participent au renouvellement des collectifs de travail. L'impact des TIC sur les conditions de travail; 2012:131.

[50] Meyer JP, Allen NJ. A three-component conceptualization of organizational commitment. HR Management Review. 1991;1(1):61-89.

[51] Fournier PS, Montreuil S, Villeneuve M, Brun JP. La charge de travail d'agents de gestion à la suite de changements technologiques. Presses de l'Université Laval, Québec. 2013:135-61.

[52] Maslach C, Jackson SE. The measrurement of experienced burnout. J of Occupa Behavior. 1981;2:99-113.

[53] Maslach C, Jackson E. The Maslach Burnout Inventory Manual, 2nd Edition, Palo-Alto, CA, Consulting Psychologists Press; 1981.

[54] Poghosyan L, Linda H, Douglas MS. Factor structure of the Maslach burnout inventory: An analysis of data from large scale cross-sectional surveys of nurses from eight countries. Inter J of Nurs Studies. 2009;46(7):894-902.

[55] Karasek R, Brisson C, Kawakami N, Houtman I, Bongers P, Amick B. The Job Content Questionnaire (JCQ): An instrument for internationally comparative assessments of psychosocial job characteristics. J of Occu Health Psychology. 1998;3(4):322.

[56] Pantenburg B, Luppa M, König HH, Riedel-Heller SG. Burnout among young physicians and its association with physicians' wishes to leave: Results of a survey in Saxony, Germany. J of Occup Med and Toxicology. 2016;11(1):2.

[57] Bentler PM, Mooijaart AB. Choice of structural model via parsimony: A rationale based on precision. Psychological Bulletin. 1989;106(2):315.

[58] Sargent LD, Terry DJ. The moderating role of social support in Karasek's job strain model. Work \& Stress. 2000;14(3):245-61.

[59] Karasek R, Theorell T. Healthy Work: Stress, Productivity and the Reconstruction of Working Life, New York, Basic Books; 1990.

[60] Ballet K, Kelchtermans G. Workload and willingness to change: Disentangling the experience of intensification. $\mathrm{J}$ of Curriculum Studies. 2008;40(1):47-67.

[61] Agha A, Mordy A, Anwar E, Saleh N, Rashid I, Saeed M. Burnout among middle-grade doctors of tertiary care hospital in Saudi Arabia. Work. 2015;51(4):839-47. 